\title{
Obesity may Increase the Prevalence of Parkinson's Disease while Parkinson's may Reduce Obesity Index in Patients
}

\section{Muslimat Kehinde Adebisi, ${ }^{1,2,3}$, Ehianeta Teddy ${ }^{4}$, Mzee Said Abdulraman Salim ${ }^{2,3}$, Liuyi $^{1,2}$, Abdul Nazif Mahmud $^{1,2,3}$, Aaron Gia Kanton ${ }^{2,3}$ and Abdullateef Taiye Mustapha ${ }^{2,3}$}

1Jiangsu University affiliated to No 1 People's Hospital Zhenjiang, Jiangsu, PRC

2Jiangsu University, Zhenjiang, PRC

${ }^{3}$ Overseas Education College of Jiangsu University, PRC

${ }^{4}$ Shanghai institute of Organic Chemistry, Chinese Academy of Sciences Shanghai, PRC

*Corresponding author: Dr Li Xuezhong, Jiangsu University affiliated to No 1, People's Hospital Zhenjiang, Jiangsu, PRC.

\begin{abstract}
Objective: Currently Parkinson's disease is becoming more common among younger people of ages from 30-40 years. The incidence is higher among patients with higher BMI, some reports has it that Obesity is a risk factor for Parkinson's disease while some reported that there is no relationship between obesity and Parkinson's disease. Parkinson's disease patient at the time of diagnosis has a above normal BMI but this goes below normal as the disease progresses. Therefore, it is important to explore the relationship between Parkinson's disease and Obesity.
\end{abstract}

Methods: 349 outpatients and inpatients with Parkinson's disease were selected from the people's Hospital affiliated to Jiangsu University from 2014.01 to 2018.12 , and 64 inpatients with non-cerebrovascular disease in the same period were selected as the control group. According to HoehnYahr grade, Parkinson's patients were divided into early stage (1 2 grade), middle stage (2.5 3 grade) and late stage (4 5 grade). The height, weight, waist circumference, total cholesterol (TC), TG (TG), high density lipoprotein cholesterol (HDL-C) and low-density lipoprotein cholesterol (LDL-C) were measured and recorded. The relationship between the severity of Parkinson's disease and blood lipid was evaluated.

Results: BMI in patients with early Parkinson's disease was higher than that in patients with other diseases, but there was no significant difference. Blood lipids in patients with early Parkinson's disease were higher than those in normal control group and in patients with advanced Parkinson's disease.
Conclusion: Obesity may increase the prevalence of Parkinson's disease, while Parkinson's may decrease the obesity index of patients with early Parkinson's disease.

\section{Keywords}

Obesity, Overweight, Metabolic syndrome, Neurodegenerative disease, Parkinson's disease, Parkinsonism

\section{Introduction}

Following Alzheimer's disease, Parkinson's disease (PD) is the second most common age-related neurodegenerative disorder. The motor-related symptoms include bradykinesia, rigidity, tremor and postural instability, while metabolic imbalances, psychiatric and cognitive disorders are typical of the non-motor symptoms [1]. Among the metabolic imbalances, several reports have correlated BMI and PD [2]. Despite evidences that report a rise in insulin resistance among PD patients, the mechanistic insights of this relationship are not fully understood a finish study emphasized on the association of over $80 \%$ of its study at high risk of PD due to history of Diabetes Mellitus (DM) while adjusting BMI [2-5]. Diets rich in fat have been reported to be a risk factor for PD while unsaturated fatty acids have been described to reduce PD risk obesity has been associated with inflammation affecting metabolism [6-9]. In the treatment

Citation: Adebisi MK, Teddy E, Salim MSA, Liuyi, Mahmud AN, et al. (2019) Obesity may Increase the Prevalence of Parkinson's Disease while Parkinson's may Reduce Obesity Index in Patients. Int J Neurodegener Dis 2:012. doi.org/10.23937/2643-4539/1710012

Accepted: October 12, 2019; Published: October 14, 2019

Copyright: (c) 2019 Adebisi MK, et al. This is an open-access article distributed under the terms of the Creative Commons Attribution License, which permits unrestricted use, distribution, and reproduction in any medium, provided the original author and source are credited. 
of obesity, chronic use of Phenetamine, a sympathomimetic agent that acts on the presynaptic vesicles in the lateral hypothalamus, stimulating $\beta 2$-adrenergic receptor hence increasing the level of Norepinephrine, dopamine and serotonin, was reported to cause PD. On the other hand, acute overdose presented classical PD symptoms such as restlessness, tremors, hyperreflexia, confusion, hallucination, and schizophrenia [10-13].

Dopamine deficiency causes a number of symptoms in which weight loss or gain, Gastroesophageal reflux (GERD) diseases are part of the presenting symptoms [7,14-22]. Uncontrolled weight gain causes maladaptation of the brain and the activation of inflammatory pathway affecting the hormonal milieu which together impacts negatively on the central nervous system (CNS). PD patients lacks enough dopamine, it is understandable they might react negatively to proper diet during the course of the disease $[23,24]$.

The years of diagnosis of PD[YOD] has been reported to affect the normal metabolic balance of the patient, disease course tends to depreciate the metabolism, bringing about tremendous weight loss as the years goes by, this could be caused as a result of the medication used in the treatment of PD. However, there has been no much report that relates YOD with $\mathrm{BMI}$, in this study we therefore examined prospectively whether the years of diagnosis of PD has a relationship with the BMI change and if obesity is a risk factor for PD.

\section{Methods}

In our study, 359 outpatients and inpatients with Parkinson's disease were selected from First People's Hospital affiliated to Jiangsu University from January 2014 to December 2018, and 74 inpatients with non-cerebrovascular disease in the same period were selected as the control group. The inclusion criteria were: i) All patients met 2017 international MDS diagnostic criteria for PD; ii) Levodopa test was positive in all patients; iii) The onset time of all Parkinson's patients can be traced back. Exclusion criteria was: i) Parkinsonism; ii) Patients with severe cardiovascular and cerebral vascular diseases; iii) Patients with severe liver and kidney insufficiency; iv) History of extracranial injury. The enrollment criteria for the control group were: I) In-hospital neurology patients in the same period; ii) The age range was $55-75$ years; iii) Parkinsonism: iv) Patients with cerebrovascular disease.

Detailed patients' history was collated, such as the age at onset of the disease presentation to determine whether it was early onset PD, and also to stage the condition based on Hoehn-Yahr gradings. Patients were divided as: Early stage (1 2 grade), Middle stage (2.5 3 grade), and Late stage ( $4 \sim 5$ grade). The height, weight, waist circumference, Total cholesterol (TC), Triglyceride (TG), High density lipoprotein cholesterol (HDL-C) and low-density lipoprotein cholesterol (LDL-C) were measured and recorded. The relationship between the severity of Parkinson's disease and blood lipid was evaluated. All the data were checked by two people, and the study passed the ethical review of ethics committee of the First People's Hospital affiliated to Jiangsu University (Table 1).

Patients' weights and heights were obtained using an electronic height weight BMI machine with ultrasonic body weighing scale following standard protocol (that is, fasting, bare feet, light clothing, erect posture and back facing the opposite side while on full inspiration). Waist circumference was taken using a standard meter scale. Blood samples were collected within 24 hours after the patient recorded data such as height and weight.

Table 1: General information on patients admitted to the group.

\begin{tabular}{|c|c|c|c|c|c|}
\hline \multirow{2}{*}{$\begin{array}{l}\text { Variable } \\
\text { Onset phase }\end{array}$} & \multicolumn{5}{|c|}{ Category of variable distribution } \\
\hline & & & & & \\
\hline Men & Control & $\leq 24 \mathrm{~m}$ & $25-72 \mathrm{~m}$ & $73-120 \mathrm{~m}$ & $>120$ \\
\hline No of cases & 29 & 47 & 68 & 15 & 25 \\
\hline Mean years & $66.11 \pm 14.52$ & $65.35 \pm 8.39$ & $69.18 \pm 10.99$ & $69.81 \pm 9.09$ & $73.17 \pm 8.17$ \\
\hline Women & Control & $\leq 24 \mathrm{~m}$ & $25-72 \mathrm{~m}$ & $73-120 \mathrm{~m}$ & $>120$ \\
\hline No of cases & 45 & 52 & 57 & 10 & 10 \\
\hline Mean years & $68.74 \pm 9.73$ & $67.48 \pm 7.22$ & $66.26 \pm 12.20$ & $77.37 \pm 11.54$ & $79.87 \pm 10.66$ \\
\hline \multicolumn{6}{|l|}{ Outset phase } \\
\hline Men & Control & $\mathrm{H}-\mathrm{Y} 1-2$ & $\mathrm{H}-\mathrm{Y} 2-2.5$ & $\mathrm{H}-\mathrm{Y} \geq 3$ & \\
\hline No of cases & 29 & 93 & 38 & 12 & \\
\hline Mean years & $66.11 \pm 14.52$ & $67.13 \pm 9.45$ & & $78.98 \pm 11.23$ & \\
\hline Women & Control & H-Y1-2 & $\mathrm{H}-\mathrm{Y} 2-2.5$ & $\mathrm{H}-\mathrm{Y} \geq 3$ & \\
\hline No of cases & 45 & 98 & 33 & 10 & \\
\hline Mean years & $68.74 \pm 9.73$ & $67.88 \pm 9.82$ & & $80.11 \pm 9.89$ & \\
\hline
\end{tabular}


Table 2: Relationship between onset time of Parkinson's disease and body mass index (n).

\begin{tabular}{|l|l|l|l|l|}
\hline Onset & $\mathbf{2 4} \mathbf{~ m}$ & $\mathbf{2 5 - 7 2} \mathbf{~ m}$ & $\mathbf{7 3 - 1 2 0 ~} \mathbf{m}$ & $>120 \mathbf{m}$ \\
\hline Male & $24.57 \pm 3.78(47)$ & $24.83 \pm 4.17(68)$ & $23.67 \pm 3.57(19)$ & $21.67 \pm 3.79^{*}(25)$ \\
\hline Female & $24.92 \pm 4.17(52)$ & $25.25 \pm 4.78(57)$ & $24.37 \pm 3.48^{*}(10)$ & $22.22 \pm 3.56^{*}(10)$ \\
\hline
\end{tabular}

Table 3: BMI relationship between Parkinson early patients and control patients (n).

\begin{tabular}{|l|l|l|l|}
\hline & No PD & Onset of PD $\leq 24 \mathbf{~ m}$ & Hoehn-Yahr 1-2 \\
\hline Male & $22.76 \pm 4.28(29)$ & $24.57 \pm 3.78(47)$ & $25.12 \pm 4.87^{*}(93)$ \\
\hline Female & $23.08 \pm 5.01(45)$ & $24.92 \pm 4.17(52)$ & $25.77 \pm 3.76^{*}(98)$ \\
\hline
\end{tabular}

Table 4: The onset time of Parkinson's disease and lipid profile between males and females.

\begin{tabular}{|l|l|l|l|l|}
\hline Onset control & $\mathbf{5 2 4} \mathbf{~}$ & $\mathbf{2 4 - 7 2} \mathbf{~}$ & $\mathbf{7 2 - 1 2 0 ~} \mathbf{m}$ & $>\mathbf{1 2 0} \mathbf{~}$ \\
\hline Males & & & & \\
\hline TC & $4.53 \pm 0.46(47)$ & $3.89 \pm 0.37(68)$ & $3.43 \pm 0.27(15)$ & $3.42 \pm 0.36^{*}(25)$ \\
\hline TG & $1.82 \pm 0.18(47)$ & $1.38 \pm 0.14^{*}(68)$ & $1.56 \pm 0.11(15)$ & $1.40 \pm 0.15(25)$ \\
\hline HDL-C & $1.19 \pm 0.12(47)$ & $1.11 \pm 0.21(68)$ & $1.51 \pm 0.17(15)$ & $1.10 \pm 0.11(25)$ \\
\hline LDL-C & $2.57 \pm 0.27(47)$ & $2.31 \pm 0.24(68)$ & $1.94 \pm 0.34(15)$ & $1.95 \pm 0.17^{*}(25)$ \\
\hline Females & & & & \\
\hline TC & $4.61 \pm 0.47(52)$ & $4.11 \pm 0.43(57)$ & $4.51 \pm 0.23(10)$ & $3.55 \pm 0.34^{*}(10)$ \\
\hline TG & $2.03 \pm 0.22(52)$ & $1.43 \pm 0.13^{*}(57)$ & $1.78 \pm 0.45^{*}(10)$ & $1.02 \pm 0.17^{*}(10)$ \\
\hline HDL-C & $1.13 \pm 0.11(52)$ & $1.20 \pm 0.14(57)$ & $0.99 \pm 0.14^{*}(10)$ & $0.77 \pm 0.11(10)$ \\
\hline LDL-C & $2.63 \pm 0.31(52)$ & $2.42 \pm 0.25(57)$ & $2.88 \pm 0.13^{*}(10)$ & $2.12 \pm 0.24^{*}(10)$ \\
\hline
\end{tabular}

\section{Statistical analysis}

SPSS 16.0 statistical software was used to analyze all the indexes. Normal test and variance homogeneity test were carried out. The mean data were expressed by mean \pm standard deviation $(x \pm s)$. Two independent sample $t$ tests were used for mean comparison, Spearman correlation analysis for univariate analysis, variance analysis for complete random design and multiple stepwise regression analysis for multivariate analysis, the difference was statistically significant $(P<0.05)$.

\section{Results}

All the patients collected were divided into less than or equal to 24 months group, 25-72 months group, 73 months- 120 months group and greater than 120 months group according to the time difference between the recording time and the onset time. The results showed that there was no significant change in the body mass index (BMI) of the patients in the first few years of diagnosis of Parkinson's disease, but the body mass index (BMI) of the patients decreased after 120 months, especially in women. The details are as follows (Table 2).

We analyzed the body mass index of patients whose onset time was less than or equal to 24 months or whose severity of Parkinson's disease was $1 \leq 2$ in Hoehn-Yahr grade. The results showed that the body mass index of patients with Parkinson's disease in early stage and within 2 years was higher than that in patients with non-cerebrovascular disease and non-Parkinson's disease, but there was no significant difference, but the body mass index of patients with Hoehn-Yahr grade $1 \leq$ 2 was higher than that of the control group, and there was statistical difference (Table 3 ).

At the same time, we analyzed the blood lipids of patients with Parkinson's disease at different onset stages, the results showed that the total blood lipids, TG, Cholesterol and LDL decreased slightly after 72 months of onset especially in 120 months and the changes were similar both men and women but more significant in women (Table 4).

We analyzed the blood lipids of patients with Parkinson's disease at the early stage and in patients with non-cerebrovascular disease and non-Parkinson's disease whose onset time was less than or equal to 24 months. The results showed that the cholesterol level of the patients whose Hoehn-Yahr grades were 1-2 was only higher than that of the control group and there were no other abnormalities (Table 5 and Table 6).

\section{Discussion}

The rapid growth in China's economy caused an increase in Obesity a risk factors for PD [25], the prevalence was estimated as 18 per 100,000 people in a survey in Shanghai, China age adjusted rates give more restricted range of $72-258.8$ per 100,000 people. Most of the reports recorded overall crude report ratio of between male and female of all ages 100 and 200 per 100,000 people [26]. However, the incidence was not mentioned in any of these reports. 
Table 5: Parkinson's disease and control group (n).

\begin{tabular}{|l|l|l|l|}
\hline & Control & Onset of PD $\leq 24$ & Hoehn-Yahr 1-2 \\
\hline Males & & & \\
\hline TC & $4.14 \pm 0.7(29)$ & $4.53 \pm 0.46(47)$ & $4.17 \pm 0.39(93)$ \\
\hline TG & $1.01 \pm 0.13(29)$ & $1.82 \pm 0.18(47)$ & $1.63 \pm 0.27^{*}(93)$ \\
\hline HDL-C & $1.37 \pm 0.45(29)$ & $1.19 \pm 0.12(47)$ & $1.13 \pm 0.21(93)$ \\
\hline LDL-C & $2.31 \pm 0.7(29)$ & $2.57 \pm 0.27(47)$ & $2.42 \pm 0.25(93)$ \\
\hline Females & & & \\
\hline TC & $4.21 \pm 0.79(45)$ & $4.61 \pm 0.47(52)$ & $4.34 \pm 0.43(98)$ \\
\hline TG & $1.09 \pm 0.15(45)$ & $2.03 \pm 0.22(52)$ & $1.79 \pm 0.28^{*}(98)$ \\
\hline HDL-C & $1.29 \pm 0.51(45)$ & $1.13 \pm 0.11(52)$ & $1.11 \pm 0.11(98)$ \\
\hline LDL-C & $2.57 \pm 0.73(45)$ & $2.63 \pm 0.31(52)$ & $2.51 \pm 0.26(98)$ \\
\hline
\end{tabular}

Table 6: Pearson's correlation showing the relationship between BMI and YOD.

\begin{tabular}{|l|l|l|l|l|l|}
\hline Height & Weight & BMI & YOD & HY & WESTER \\
\hline $\mathbf{1}$ & 0.463 & 0.157 & -0.276 & -0.010 & 0.016 \\
\hline $\mathbf{0 . 4 6 3}$ & 1 & 0.899 & -0.407 & -0.393 & -0.051 \\
\hline $\mathbf{0 . 1 5 7}$ & 0.899 & 1 & -0.569 & -0.651 & -0.184 \\
\hline $\mathbf{- 0 . 2 7 6}$ & -0.407 & -0.569 & 1 & 0.746 & 0.516 \\
\hline $\mathbf{- 0 . 0 1}$ & -0.393 & -0.651 & 0.746 & 1 & 0.160 \\
\hline $\mathbf{0 . 0 1 6}$ & -0.051 & -0.184 & 0.516 & 0.160 & 1 \\
\hline
\end{tabular}

Table 4 describes how the lipid profile kept declining as the years of diagnosis increase and Table 5 compared different lipid elements with controlled group at an early stage of the disease the blood lipid was higher than those patients with advanced Parkinson's disease.

From Table 2 and Table 3, We found that the body mass index of the patients with onset time within 24 months was higher than that of the control group, but there was no significant difference and the body mass index of the patients with Hoehn-Yahr 1- 2 was higher than that of the control group, suggesting that the body mass index of the early patients was higher than that of the control group. The reason for the patient's non-significant difference in the 24-month period might be because the number of patients was not that much. Walker RW HA, et al. reported an inverse relationship between the severity of PD and BMI [27], lack of association in all other studies might be because of the short duration of our report because our study recorded duration ranging from the past 5 years, shown in months on Table 1 .

Table 4 and Table 5 showed the relationships of lipid profile as TC, TG, LDL, HDL, LDL-C, HDL-C with BMI as disease progresses in months, Blood lipids in patients with early Parkinson's disease were higher than those in normal control group and in patients with advanced Parkinson's disease. Ga Eun Nam1 SMK, et al. his studies reported a relationship between weight gain and deep brain stimulation (DBS) likewise a Korean study reported a relationship between metabolic syndrome (Mets) and PD [28].

Table 6 Pearson's correlation analysis was performed on the parameters and the result is as shown as expected, BMI showed a great positive correlation with weight, which indicates that the two parameters are highly dependent on each other and as one increases the other increases as well. A similar trend is also observed with $\mathrm{HY}$ staging and years of diagnosis (YOD) with 0.746 , followed by wester and YOD then weight and height. This also indicates that any of the parameter can be taken on a patient and it will suffice for the diagnosis, most of the other parameters showed a negative correlation which signifies that as one increases the other decreases. However, the correlation is not so high except for the YOD and $\mathrm{BMI}$ with -0.569 , from this result it can be ascertained that there is $50 \%$ chance that years of diagnosis has effect on BMI.

Finally, there is a lot of controversy about the relationship between $\mathrm{BMI}$ and $\mathrm{PD}$ because overweight, normal weight, underweight can all be present depending on individual and how well managed the disease is [6].

\section{Conclusion}

In summary, the results of our study showed that: i) Obesity may increase the prevalence of Parkinson's disease. ii) The body mass index of patients with Parkinson's disease shows two-way changes in different periods, and the body mass index is higher, and cholesterol is higher in the early stage of Parkinson's disease. Attention should be paid to these metabolic diseases that not only disrupt the system but also affects the medication used decreasing the chances of proper PD management. Neurologist should work hand in hand with endocrinologist and nutritionist to follow up on PD patients for proper management and prognosis.

\section{References}

1. Chaudhuri KR, Healy DG, Schapira AH (2006) Non-motor symptoms of parkinson's disease: Diagnosis and management. Lancet Neurol 5: 235-245. 
2. Palacios N, Gao X, McCullough ML, Jacobs EJ, Patel AV, et al. (2011) Obesity, diabetes and risk of parkinson disease. Mov Disord 26: 2253-2259.

3. Craft S, Watson GS (2004) Insulin and neurodegenerative disease: Shared and specific mechanisms. Lancet Neurol 3: 169-178.

4. Kahn SE, Hull RL, Utzschneider KM (2006) Mechanisms linking obesity to insulin resistance and type 2 diabetes. Nature 444: 840-846.

5. Hu G, Jousilahti P, Bidel S, Antikainen R, Tuomilehto J (2007) Type 2 diabetes and the risk of parkinson's disease. Diabetes Care 30: 842-847.

6. Chen J, Guan Z, Wang L, Song G, Ma B, et al. (2014) Meta-analysis: Overweight, obesity, and parkinson's disease. Int J Endocrinol 2014: 1-7.

7. Chen $\mathrm{H}$, Zhang SM, Schwarzschild MA, Hernán MA, Willett WC, et al. (2004) Obesity and the risk of parkinson's disease. Am J Epidemiol 159: 547-555.

8. Whitmer RA, Gunderson EP, Barrett-C, Queensberry CP $\mathrm{Jr}$, Yaffe K (2005) Obesity in middle age and future risk of dementia: A 27-year longitudinal population-based study. BMJ 330: 1360.

9. Barmore R, Hess C, McFarland N, Okun M (2018) A case of tardive dyskinesia and parkinsonism following use of phentermine for weight loss. Neurology 082.

10. Hendricks EJ (2017) Off-label drugs for weight management. Diabetes Metab Syndr Obes 10: 223-234.

11. Singh J, Kumar R (2015) Phentermine-topiramate: First combination drug for obesity. Int J Appl Basic Med Res 5: 157-158.

12. Ryder JR, Kaizer A, Rudser KD, Gross A, Kelly AS, et al. (2017) Effect of phentermine on weight reduction in a pediatric weight management. Int J Obes 41: 90-93.

13. Meguid MM, Fetissov SO, Varma M, Sato T, Zhang L, et al (2000) Hypothalamic dopamine and serotonin in the regulation of food intake. Nutrition 16: 843-857.

14. Schwartz MW, Wood S, Porte D, Seeley RJ, Baskin DG (2000) Central nervous system control of food intake. Nature 404: 661-671.

15. Langston JW, Forno LS (1978) The hypothalamus in parkinson disease. Ann Neurol 3: 129-133.
16. Shannak K, Rajput A, Rozdilsky B, Kish S, Gilbert J, et al. (1994) Noradrenaline, dopamine and serotonin levels and metabolism in the human hypothalamus: Observations in parkinson's disease and normal subjects. Brain Res 639: 33-41.

17. Lill CM (2016) Genetics of parkinson's disease. Mol Cell Probes 30: 386-396.

18. Delamarre A, Meissner WG (2017) Epidemiology, environmental risk factors and genetics of parkinson's disease. Presse Med 46: 175-181.

19. Singleton AB, Farrer MJ, Bonifati $V$ (2013) The genetics of parkinson's disease: Progress and therapeutic implications. Mov Disord 28: 14-23.

20. Pei Z, Bo T (2014) Metabolic syndrome: An important risk factor for parkinson's disease. Oxid Med Cell Longev 2014: 729194.

21. Abbott RD, Ross GW, White LR, Nelson JS, Masaki KH, et al. (2002) Midlife adiposity and the future risk of parkinson's disease. Neurology 59: 1051-1057.

22. Lee EB, Mattson MP (2014) The neuropathology of obesity: Insights from human disease. Acta Neuropathol 127: 3-28.

23. Hu G, Jousilahti P, Nissinen A, Antikainen R, Kivipelto M, et al. (2006) Body mass index and the risk of parkinson diseases. Neurology 67: 1955-1959.

24. Chen CM (2008) Overview of obesity in mainland China. Obes Rev 9: 14-21.

25. Morales-Briceno $H$, Cervantes-Arriaga A, Rodríguez-Violante M, Calleja-Castillo J, Corona T (2012) Overweight is more prevalent in patients with parkinson's disease. Arq Neuropsiquiatr 70: 843-846.

26. Walker RW, Howells AR, Gray WK (2011) The effect of levodopa dose and body weight on dyskinesia in a prevalent population of people with parkinson's disease. Parkinsonism Relat Disord 17: 27-29.

27. Nam GE, Kim SM, Han K, Kim NH, Chung HS, et al. (2018) Metabolic syndrome and risk of parkinson disease: A nationwide cohort study. PLoS Med 15: e1002640.

28. Hélio AGT (2012) Doença de parkinson e índice de massa corporal: Excesso ou falta de peso? Arq Neuropsiquiatr 70: 837-838. 